\title{
Surface plasmon resonance of $\mathrm{Ag}$ organosols: Experimental and theoretical investigations
}

\author{
Ivana Vukoje ${ }^{1}$, Dušan Božanić ${ }^{1}$, Jasna Džunuzović ${ }^{2}$, Una Bogdanović ${ }^{1}$, Vesna Vodnik ${ }^{1}$ \\ ${ }^{1}$ University of Belgrade, Vinča Institute of Nuclear Sciences, Belgrade, Serbia \\ ${ }^{2}$ University of Belgrade, Institute of Chemistry, Technology and Metallurgy (ICTM) - Center of Chemistry, Belgrade, \\ Serbia
}

\begin{abstract}
The aim of this study was to investigate and compare the changes in surface plasmon resonance (SPR) of silver (Ag) hydrosol and organosols obtained by experimental and theoretical approaches. Silver nanoparticles (Ag NPs) of $5 \pm 1.5 \mathrm{~nm}$ in diameter were prepared in water by reduction of silver nitrate with sodium borohydride. Nanoparticles were subsequently transferred into different organic solvents (chloroform, hexane, toluene, 1,2-dichlorobenzene) using oleylamine as a transfer agent. These solvents were chosen because of the differences in their refractive indices. Using UV-Vis absorption spectrophotometry and transmission electron microscopy (TEM), we confirmed that there were no shape and size changes of the nanoparticles upon the transfer to the organic phase. The absorption spectra of the obtained Ag organosols showed changes only in the position of the SPR band depending on the dielectric property of the used solvent. To analyze these changes, absorption spectra were modelled using Mie theory for small spherical particles. The experimental and theoretical resonance values were compared with those predicted by the Drude model and its limitations in the analysis of absorption behavior of Ag NPs in organic solvents were briefly discussed.
\end{abstract}

Keywords: silver nanoparticles; organosol; Mie theory; Drude model.

\section{SCIENTIFIC PAPER}

UDC 620.1:546.57:535.342

Hem. Ind. 66 (6) 805-812 (2012)

doi: 10.2298/HEMIND120112028V

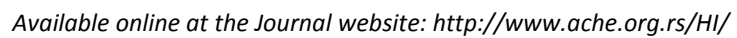

The investigation of the specific features of metal nanoparticles have been the subject of the numerous studies for a long time, due to their unique electronic, optical, chemical and magnetic properties, that are different from those of the individual atoms as well as from their bulk counterparts [1-5]. Nanoparticles composed of noble metals such as $\mathrm{Au}$ and $\mathrm{Ag}$ exhibit strong absorption of electromagnetic radiation in the visible region, which is often referred to as a surface plasmon resonance (SPR) property. Such resonance occurs when the frequency of the incident light is resonant with the collective oscillation of the conduction band electrons of metal nanoparticles. The position and width of the SPR band of metal colloids are strongly influenced by the size, shape and the environment of the particles, and deeper understanding of these effects is necessary for understanding the optical properties of these systems [6-8]. It is well known that Mie, in 1908, was the first to develop the theory of absorption and scattering of light by spherical particles [9]. The calculations of absorption spectra of metallic nanoparticles clearly reflect the well-known dependence of nanoparticle optical properties, i.e., the resonance wavelength, the ex-

Correspondence: V. Vodnik, Vinča Insitute of Nuclear Sciences, P.O. Box 522, 11001 Belgrade, Serbia.

E-mail: vodves@vinca.rs

Paper received: 12 January, 2012

Paper accepted: 9 March, 2012 tinction cross-section, and the ratio of scattering to absorption, on the nanoparticle dimensions. On the other hand, the effects of the particle environment on the SPR band are manifested by a red-shift of the resonance wavelength with the increase of the refractive index of the surrounding medium. These effects have been used for sensor applications [10-12]. In addition, metal nanoparticles have also found application in many different fields such as biochemistry, photography or catalysis [13-18].

Thus far, a variety of synthetic methods has been reported for metallic nanoparticles synthesis [19-25]. One of the main challenges in the preparation of metal colloids is developing a way to obtain the nanoparticles in specific physicochemical environments, such as organic nonpolar liquids, specific regions within ordered surfactant phases and monolayer assemblies [26-28]. The understanding of the physicochemical properties of metal organosols is important to their potential use in future photonic applications [27, 29-35]. The silver organosols display several advantages over silver hydrosols, such as the ability to be isolated and re-dissolved in solvents without irreversible aggregation, stability in air, and so forth. Attempts have been made to obtain nearly monodisperse Ag NPs in different nonpolar solvents - chloroform, hexane, toluene, dichlorobenzene, etc. In this study, we synthesized Ag NPs in water and then transferred them into organic solvents 
by simple surface modification using oleylamine as surfactant. A capping agent (oleylamine) was used to protect the particles from aggregation. Theoretical and experimental aspects of the optical properties of $\mathrm{Ag}$ NPs in different solvents have been discussed. Special attention was paid to the correlation between nanoparticles environment and their optical properties.

\section{EXPERIMENTAL}

\section{Materials}

Silver nitrate $\left(\mathrm{AgNO}_{3}\right)$, sodium borohydride $\left(\mathrm{NaBH}_{4}\right)$, oleylamine, chloroform, hexane, toluene, and 1,2-dichlorobenzene were purchased from Merck and used as received. Milli-Q deionized water was used for synthesis.

\section{Preparation of silver sols}

Silver hydrosol was prepared by the reduction of silver ions using $\mathrm{NaBH}_{4}$, as described elsewhere [24,36]. Typically, $10 \mathrm{mg}$ of $\mathrm{NaBH}_{4}$ was added into $250 \mathrm{ml}$ of argon-saturated solution of $5 \times 10^{-4} \mathrm{M} \mathrm{AgNO}_{3}$. Yellow silver hydrosol was formed immediately without any additional stabilizer. Due to hydrolysis of excess $\mathrm{NaBH}_{4}$, $\mathrm{pH}$ increased and reached value of 9.8. The silver hydrosol was stable several hours in argon atmosphere.

The transfer of Ag NPs from the hydrosol into organic phase (chloroform) was performed using oleylamine as transfer agent. To do so, $250 \mathrm{ml}$ of $5 \times 10^{-4} \mathrm{M}$ prepared hydrosol was mixed with $25 \mathrm{ml}$ of chloroform containing $1.5 \times 10^{-2} \mathrm{M}$ oleylamine and stirred vigorously. Two layers with a clean boundary in the bottle were observed. The bottom layer became yellowbrownish while the upper aqueous layer became colorless, evidently due to the transfer of Ag NPs from the aqueous phase to the organic phase. This can be confirmed from the photographs of Ag NPs in both aqueous and organic phases (see insets of Figures 1 and 3). Silver NPs in other organic solvents, beside chloroform, were prepared by evaporating chloroform from the 1 $\mathrm{ml}$ of initial organosol and subsequent re-dispersion of the sediment into equal amount of hexane, toluene, and 1,2-dichlorobenzene. All prepared Ag organosols were stable for at least few months with no evident changing.

\section{Apparatus}

The size distributions of Ag NPs were determined using a Philips EM-400 transmission electron microscope (TEM) operating at $100 \mathrm{kV}$. The samples were prepared by placing a drop of silver colloid onto a carbon-coated $\mathrm{Cu}$ grid, which was allowed to dry in air. Concentrations of the Ag NPs in water and chloroform used to prepare TEM samples were 0.054 and 0.54 $\mathrm{mg} / \mathrm{ml}$, respectively.
UV-Vis absorption spectra of the silver hydrosol and organosols were acquired by using a Termoscientific Evolution 600 spectrophotometer at room temperature.

\section{RESULTS AND DISCUSSION}

The strong reducing agent (sodium borohydride) produced a sol containing silver particles, whose average diameter was smaller than the wavelength of visible light. During chemical reduction of silver ions, silver atoms are formed, aggregating into nuclei of a new phase, which can grow and yield stable Ag NPs. An important role for the final particle distribution is played by agglomeration of very small, primarily formed particles. The shape and size distribution of prepared $\mathrm{Ag}$ NPs were examined by TEM and a representative image of silver hydrosol and its photograph are given in Figure 1a. It can be seen that the NPs are mainly spherical and isolated. Although we did not use any stabilizing agents in the preparation procedure, the absence of aggregates in the sample can be attributed to the adsorption of $\mathrm{B}(\mathrm{OH})_{4}^{-}$on the surface of nanoparticles [36]. According to this, particle stability is achieved through the electrostatic repulsion between the negatively charged Ag NPs. Based on TEM measurements, the corresponding particle size distribution is presented in Figure 1b. The particle sizes were between 4 and 7 $\mathrm{nm}$ with an average diameter $d_{\mathrm{av}}=5.6 \mathrm{~nm}$ and polydispersity $32 \%$. Polydispersity represents the ratio between the full width at half maximum (FWHM) and average diameter of Ag NPs according to Figure $1 \mathrm{~b}$.

The UV-Vis absorption spectrum of the initial $\mathrm{Ag}$ hydrosol (Figure 2a) shows intensive absorption of $\mathrm{Ag}$ NPs arising from the collective oscillations of the free conduction band electrons that are induced by the incident electromagnetic radiation. The yellow color of the hydrosol is a manifestation of narrow SPR band with maximum at around $389 \mathrm{~nm}$. To model observed absorption spectra of silver colloids, we used Mie theory [9] for the calculation of the optical properties of Ag NPs. According to the theory, the extinction efficiency $Q_{\text {ext }}$ of a single small metallic sphere of radius $r$ in a dielectric environment with dielectric constant $\varepsilon_{m}$ is given by:

$Q_{\text {ext }}(\lambda)=4 x \operatorname{Im}\left\{\frac{\varepsilon(\lambda)-\varepsilon_{m}}{\varepsilon(\lambda)+2 \varepsilon_{m}}\right\}$

where $x=\sqrt{\varepsilon_{m}} k r$ and $k=2 \pi / \lambda$. In the preceding relation, $\varepsilon(\lambda)$ stand for complex dielectric function of silver nanoparticles, which is in our study obtained using the HaO and Nordlander fit [37] of the Johnson and Christy experimental data for bulk silver [38] and after appropriate correction for small particle size according to Hovel et al. [39] (Figure 2b). Theoretical absorption 

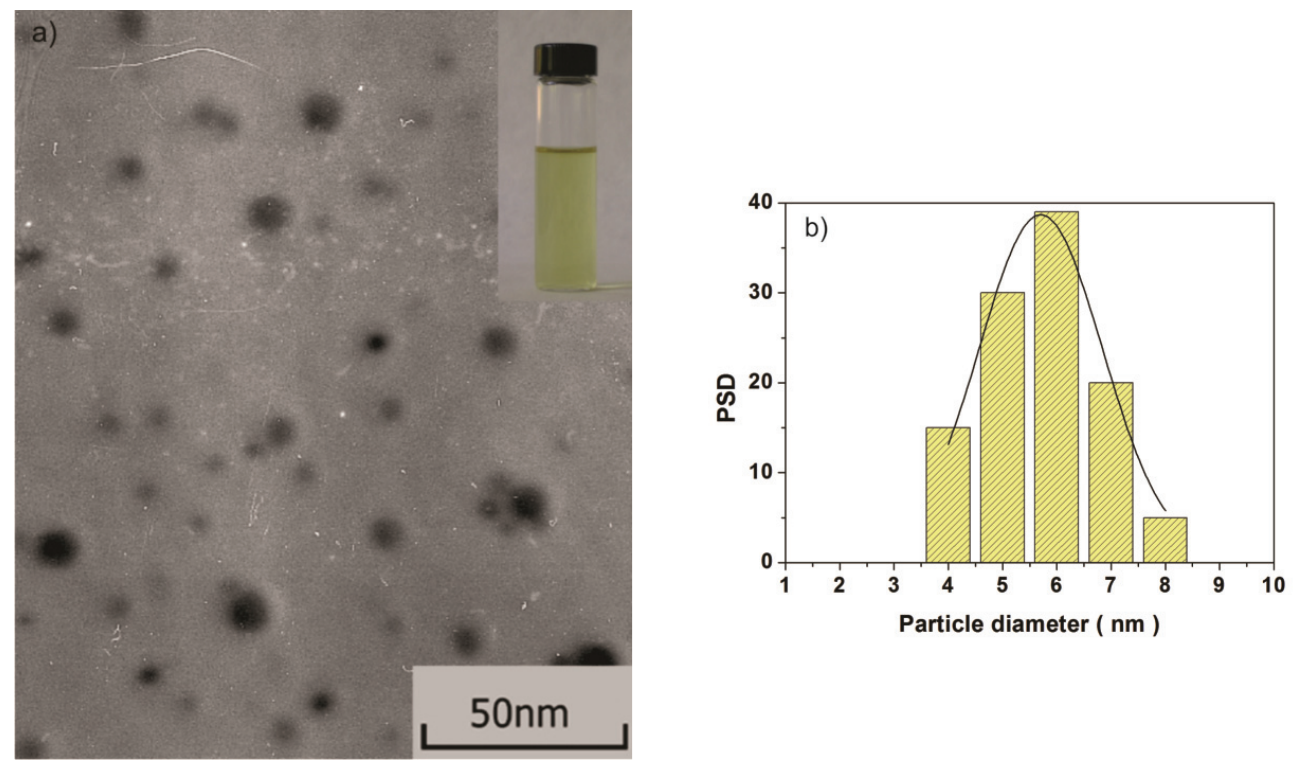

Figure 1. Typical TEM image of Ag NPs with photograph of Ag hydrosol (a) and corresponding particle size distribution (PSD) (b).

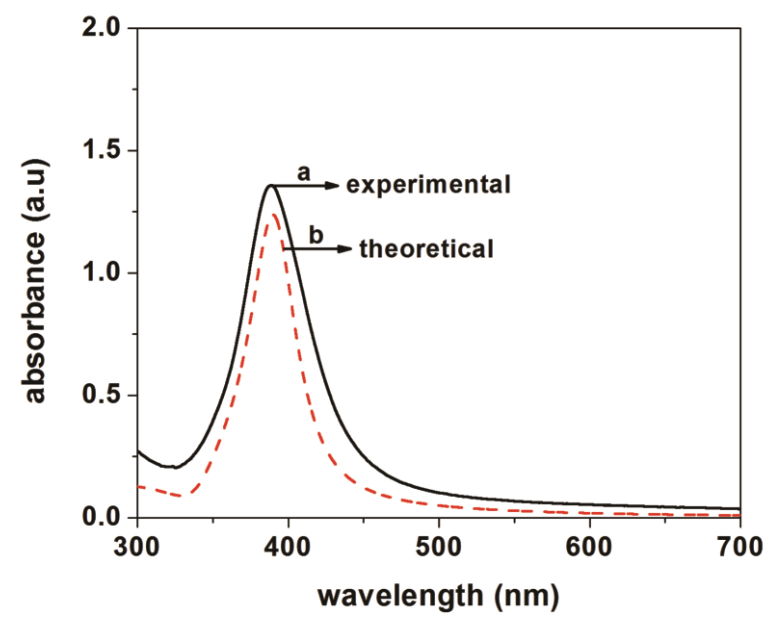

Figure 2. Experimental (solid black line, a) and theoretical (dashed red line, b) UV-Vis absorption spectra of Ag NPs.

band for $5 \mathrm{~nm} \mathrm{Ag} \mathrm{NPs}$ in water (refractive index $n=$ $=1.33$ ) is given in Figure $2 \mathrm{~b}$. It can be seen that the main features of the experimental spectrum are reproduced by Mie theory. Furthermore, the theoretical band is positioned at $390 \mathrm{~nm}$, which is in good agreement with the experimental measurement.

To achieve the phase transfer of Ag NPs from water into nonpolar organic solvents, it was necessary to use a surfactant that forms adsorption layer on the Ag NPs. The oleylamine was used as a capping agent, which enabled the phase transfer and prevented particle aggregation, oxidation and degradation, as well as to render the particle surface hydrophobic. The oleylamine-capped metal particles are actually kinetically rather than thermodynamically stabilized and their interactions are considered to be quite weak [40]. The
Ag NPs in organic solvents were also characterized by TEM measurements. As an example, a typical TEM image of the Ag NPs in the chloroform is shown in Figure 3 (TEM images of other Ag organosols are not shown). The TEM image clearly indicates that transfer of Ag NPs to chloroform resulted in their spontaneous organization in two-dimensional (2D) close-packed arrays, and has no influence on the particles morphology and size. This is a consequence of high concentration of silver particles in chloroform and low polydispersity of the system. Based on TEM investigations, the average diameter of the Ag NPs after phase transfer was $6.5 \mathrm{~nm}$ (histogram, Figure 3).

In addition, the oleylamine-capped Ag NPs were effectively transferred in a similar fashion to other organic solvents, such as hexane, toluene and 1,2-dichloro- 

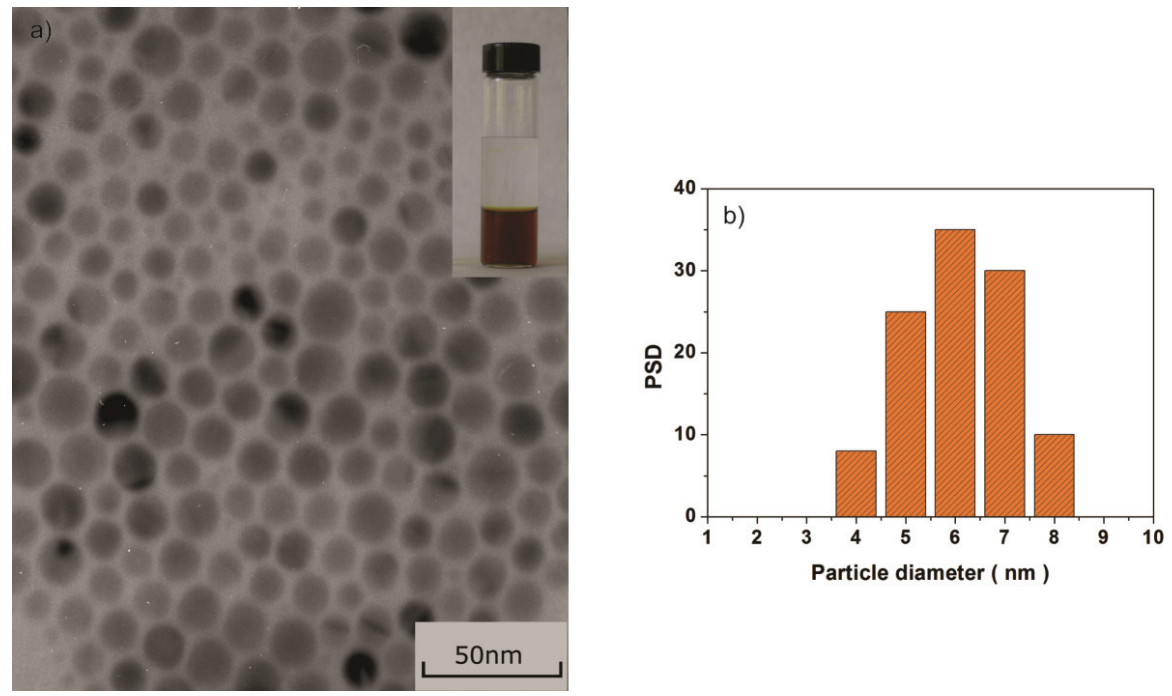

Figure 3. TEM Image of Ag NPs in chloroform and its photograph (a) with corresponding particle size distribution (b).

benzene, and the UV-Vis spectra of all organosols are presented in Figure 4 (experimental curves). In all cases, the spectra show that the organosols exhibit intensive and narrow absorption bands, which indicates that there was no aggregation of the particles upon the phase transfer. The obtained narrow half-width of the SPR band also implies that prepared Ag NPs are highly uniform. This conclusion can be further supported by calculating the extinction efficiencies of the obtained organosols (Eq. (1)) since Mie theory describes absorption behavior of non-interacting spherical nanoparticles. As can be seen in Figure 4 (red lines), the theoretical spectra of silver organosols show good agreement to those obtained experimentally.

On the other hand, the only difference that can be observed between absorption spectra of the Ag nano-
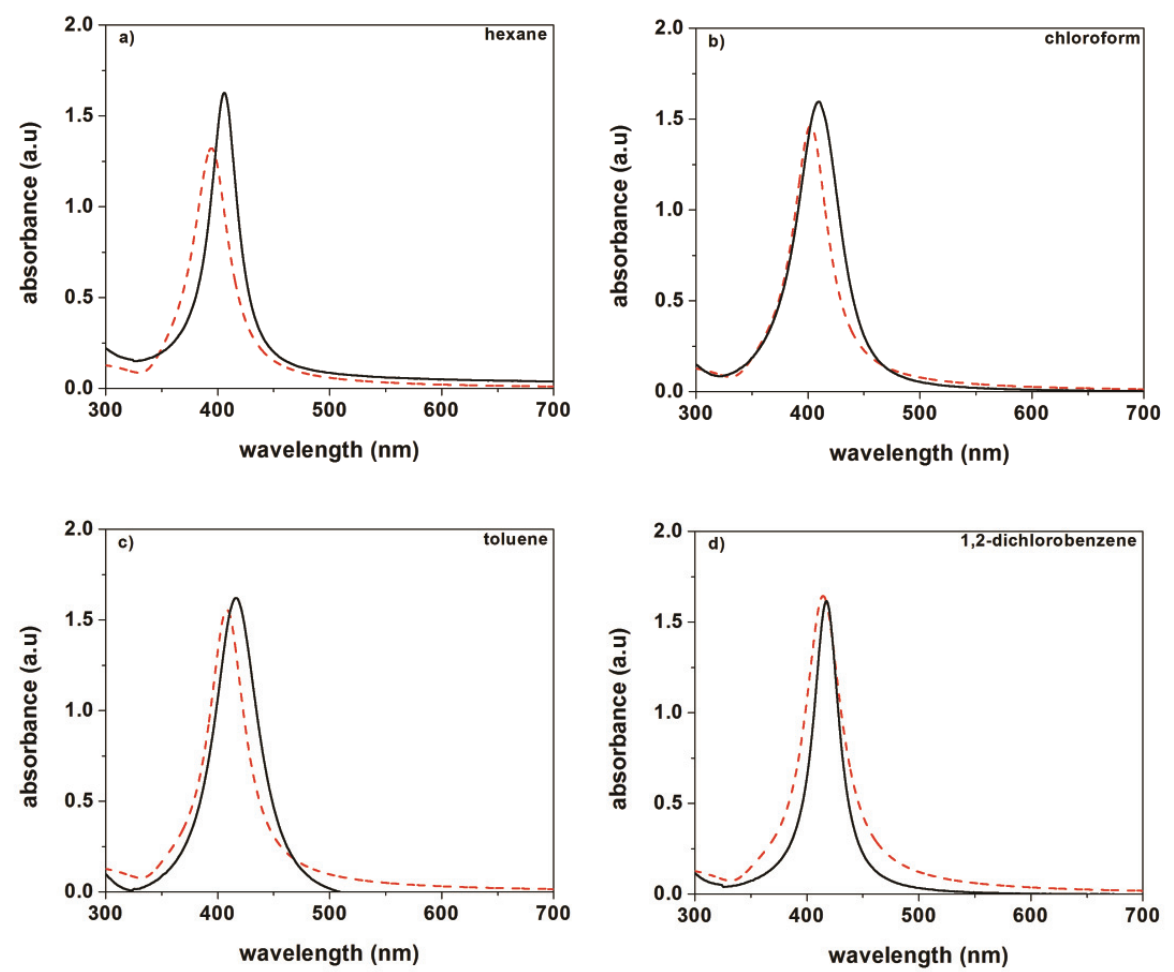

Figure 4. Comparison of experimental (solid black line) and theoretical (dashed red line) UV-Vis absorption spectra of Ag NPs in hexane (a), chloroform (b), toluene (c), and 1,2-dichlorobenzene (d). 
particles in water and organic solvents is that the peak position of the surface plasmon resonance of $\mathrm{Ag}$ organosols is red shifted in comparison to the absorption spectra obtained for Ag hydrosol. This is a consequence of the different nanoparticles environments (i.e., solvents). These particular solvents were chosen because of the distinctive difference in their refractive index. Namely, according to Drude theory [41], dielectric constant of the surrounding medium exclusively determines the plasmon peak position. Therefore, by changing the environment in which nanoparticles are dispersed we can alter their resonant absorption. In other words, by controlling the dielectric constant of the surrounding medium we can predict the wavelength of the SPR band, which can be used for optical applications of these nanoparticles. The process of solvent change from water to nonpolar solvents should lead to a red shift of the plasmon band, due to the higher refractive index of these solvents with respect to that of water. As an example, the SPR band of Ag NPs in chloroform (peak position at $410 \mathrm{~nm}$ ) is red-shifted for about $21 \mathrm{~nm}$ compared to the position of plasmon band of the Ag hydrosol. The details of the maximum peak position and refractive index of used solvents are summarized in Table 1.

Table 1. Experimentally obtained and calculated absorption maximum $\lambda_{\max }$ of Ag NPs in different solvents of varying refractive index $n$

\begin{tabular}{lccc}
\hline \multirow{2}{*}{ Solvent } & \multicolumn{2}{c}{$\lambda_{\max } / \mathrm{nm}$} & \multirow{2}{*}{$n$} \\
\cline { 2 - 3 } & Experimental & Theoretical & \\
\hline Water & 389 & 390 & 1.333 \\
Hexane & 406 & 394 & 1.375 \\
Chloroform & 410 & 402 & 1.445 \\
Toluene & 417 & 402 & 1.497 \\
1,2-Dichlorobenzene & 418 & 417 & 1.551 \\
\hline
\end{tabular}

Thus far, the theoretical calculation of Ag NPs absorption bands employed experimental values of the dielectric constants of Ag taken from [38]. To analyze the changes in SPR position further we can use Drude equation for the dielectric function of Ag NPs given by:

$\varepsilon(\omega)=\varepsilon_{\infty}-\frac{\omega_{p}^{2}}{\omega^{2}+i \omega \Gamma}$

since this equation describes absorption behavior well in the vicinity of the peak position. In the equation $2, \varepsilon_{\infty}$ represents the contribution of the vacuum and interband electronic transitions, $\omega_{p}$ is the bulk plasmon frequency, and:

$\Gamma=\Gamma_{0}+\mathrm{A} \frac{v_{\mathrm{F}}}{r}$ is the size dependent damping frequency, $\Gamma_{0}$ is the bulk damping frequency, $v_{\mathrm{F}}$ Fermi velocity, and $A$ is the theory dependent parameter that includes details of scattering process. By introducing Eq. (2) into the Eq. (1) for extinction efficiency, one can obtain following relation for the surface plasmon peak position:

$\lambda_{c}=\frac{2 \pi c}{\omega_{p}} \sqrt{\varepsilon_{\infty}+2 \varepsilon_{m}}$

It can be seen that the $\lambda_{c}$ values depend solely on $\varepsilon_{m}$, since $\varepsilon_{\infty}$ and $\omega_{p}$ are assumed constant for a given metal. Note that the refractive index of the medium is directly related to its dielectric constant $\left(\varepsilon_{m}=n^{2}\right)$.

The SPR positions as a function of dielectric constant estimated from the absorption bands of the prepared colloids, as well as those obtained using Mie theory are given in Figure 5a. It can be seen that the $\lambda_{c}$ values increase with the increase of the $\varepsilon_{m}$ as predicted by Eq. (4) (black line in the Figure 5a). The $\lambda_{c}\left(\varepsilon_{m}\right)$ dependence (Eq. (4)) was determined using the following parameters for silver: $\omega_{p}=9.5 \mathrm{eV}, \Gamma_{0}=0.1 \mathrm{eV}, \varepsilon_{\infty}=5$, $V_{\mathrm{F}}=1.4 \times 10^{6} \mathrm{~m} / \mathrm{s}$ and $A=1$ [42]. One can notice that for given $\varepsilon_{m}$, the $\lambda_{c}$ values of the experimental and theoretical curves are somewhat higher than those obtained using Eq. (4). The reason for these differences is the underestimated $\varepsilon_{\infty}$, and to demonstrate that we fitted our experimental and theoretical data with the function:

$F\left(\varepsilon_{m}\right)=\left(\frac{\lambda_{c} \omega_{p}}{2 \pi c}\right)^{2}=\left(\varepsilon^{\prime}+2 \varepsilon_{m}\right)$

in which the proper $\mathcal{E}^{\prime}$ values are determined for the dielectric constant of silver at high frequencies. The results of this analysis are given in Figure $5 \mathrm{~b}$ and $F\left(\varepsilon_{m}\right)$ fits yield $\varepsilon^{\prime}=5.7$ and $\varepsilon^{\prime}=5.3$ for the experimental and theoretical data, respectively. It is important to note that theoretical curves were obtained using experimental data for the calculation of dielectric function of $\mathrm{Ag}$ NPs. Therefore, for the a priori estimation of Ag NPs peak position in organic solvents by Eq. (4) we suggest that it would be more accurate to use higher value for the dielectric constant of silver at high frequencies $\left(\varepsilon_{\infty}=5.5 \pm 0.2\right)$. Bearing in mind that $\varepsilon_{\infty}=1+\chi$, where $\chi$ represents the contribution of the interband transitions, one can conclude that inner electrons influence the absorption behavior of silver nanoparticles in organic solvents. However, the difference between the Drude model predicted and experimental peak positions cannot be attributed solely to this effect, since additional processes in silver organosols can occur, such as charge transfer between the nanoparticles surface and solvent molecules, which result in lowering of the plasmon frequency value $\omega_{p}$ [43]. 


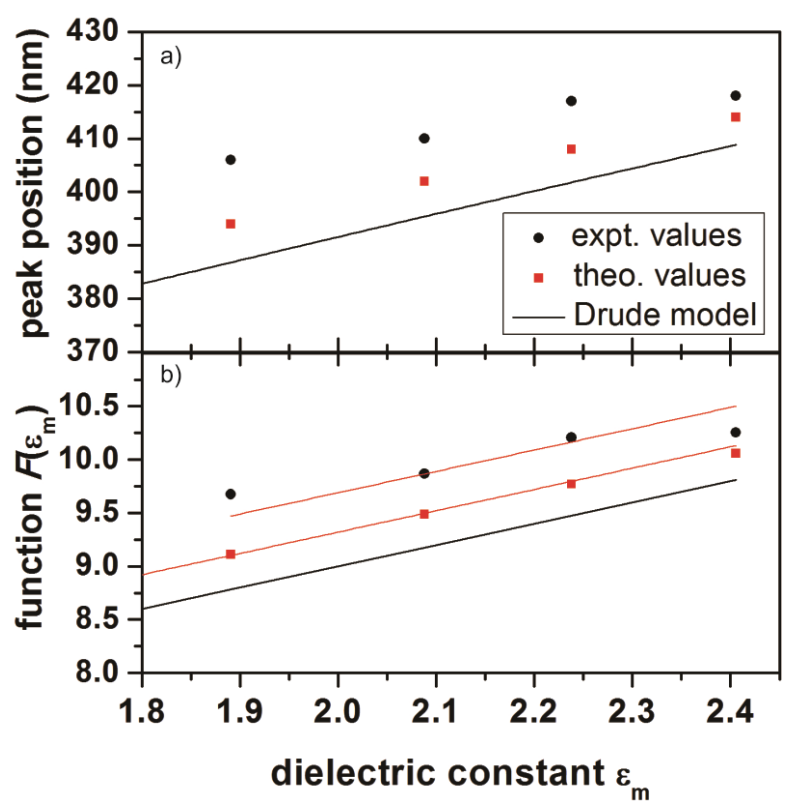

Figure 5. a) Experimental (circles) and theoretical (squares) values of surface plasmon peak positions and b) fit to $F\left(\varepsilon_{m}\right)$ given by Eq. 5 (black bottom line) of Ag NPs as a function of dielectric constant.

\section{CONCLUSION}

A simple method of phase transfer Ag NPs with narrow size distribution from water to nonpolar organic solvents is described. The oleylamine served as both a transfer and a surface capping agent. The so prepared hydrophobic nanoparticles were stable and readily redispersable in a variety of nonpolar solvents. From the UV-Vis absorption spectra and TEM images, we confirmed that there were no shape and size changes of the nanoparticles upon transfer to the organic phase. Theoretical bands, calculated by Mie theory using experimental data for the calculation of dielectric function of Ag NPs, confirmed experimentally gained redshift of SPR band, after the phase transfer due to the increase in dielectric constant of the particles environment. The slight disagreement between experimental and theoretical curves obtained by Drude relation for the SPR peak position is attributed to underestimated value for the dielectric constant of silver at high frequencies. Therefore, after fitting experimental and theoretical data for estimation of Ag NPs peak position in organic solvent we concluded that it would be more appropriate to use higher value for the dielectric constant of silver at high frequencies $\varepsilon_{\infty}=5.5 \pm 0.2$.

The curves obtained in this way may be used to characterize the Ag NPs in different media. Furthermore, this method of phase transfer can also be applied for efficient transfer of other metal nanoparticles, such as $\mathrm{Au}$ and $\mathrm{Cu}$, to various nonpolar organic solvents. The advantages of such organosols can be found in the applications of metal particles as catalysts and open the possibility for their interaction with polymers or organic dyes to obtain composites for fundamental optical studies and applications.

\section{Acknowledgements}

This work was financially supported by the Ministry of Education, Science and Technological Development of the Republic of Serbia (research project numbers: 172056 and 45020).

\section{REFERENCES}

[1] T. Linnert, P. Mulvaney, A. Henglein, Surface chemistry of colloidal silver: Surface plasmon damping by chemisorbed iodide, hydrosulfide ( $\mathrm{SH}-$ ) and phenilthiolate, J. Phys. Chem., B 97 (1993) 679-682.

[2] A. Henglein, D. Meisel, Radiolytic control of the size of colloidal gold nanoparticles, Langmuir 14 (1998) 7392$-7396$.

[3] S. Link, M.A. El-Sayed, Size and temperature dependence of the plasmon of colloidal gold nanoparticles, J. Phys. Chem., B 103 (1999) 4212-4217.

[4] M.M. Alvarez, J.T. Khoury, T.G. Schaaff, M.N. Shafigullin, I. Vezmar, R.L. Whetten, Optical absorption spectra of nanocrystal gold molecules, J. Phys. Chem., B 101 (1997) 3706-3712.

[5] J.R. Hea, C.M. Knobler, D.V. Leff, Pressure/temperature phase diagrams and superlattices of originally functionalized metal nanocrystal monoleyers: The influence of particle size, size distribution, and surface passivant, J. Phys. Chem., B 101 (1997) 189-197.

[6] S. Underwood, P. Mulvaney, Effect of the solution refractive index on the color of gold colloids, Langmuir 10 (1994) 3427-3430. 
[7] U. Kreibig, M. Gartz, A. Hilger, H. Hovel, Mie-plasmon spectroscopy: A tool of surface science. In: E. Pelizzatti, (Ed.), Fine Particles Science and Technology, Kluwer Academic Publishers, Boston, 1996, p. 499.

[8] A. Henglein, M. Giersig, Formation of colloidal silver nanoparticles: Capping action of citrate, J. Phys. Chem., B 103 (1999) 9533-9539.

[9] G. Mie, Beitrage zur optic truber medien, Ann. Physik 25 (1908) 377-445.

[10] F. Meriaudeau, T.R. Downey, A. Passian, A. Wig, T.L. Ferrell, Enviroment effects on surface-plasmon spectra in gold-island films potential for sensing applications, Appl. Opt. 37 (1998) 8030-8037.

[11] F. Meriaudeau, A. Wig, A. Passian, T. Downey, M. Buncick, T.L. Ferrel, Gold island fiber optic sensor for refractive index sensing, Sens. Actuators B 69 (2000) 51$-57$.

[12] T. Okamoto, I. Yamaguchi, T. Kobayashi, Local plasmon sensor with gold colloid monolayers deposited upon glass substrates, Opt. Lett. 25 (2000) 372-374.

[13] T.K. Sau, C.J. Murphy, Room Temperature, high-yield synthesis of multiple shapes of gold nanoparticles in aqueous solution, J. Am. Chem. Soc. 126 (2004) 8648$-8649$.

[14] A.S.K. Hashmi, Gold-catalyzed organic reactions, Chem. Rev. 107 (2007) 3180-3211.

[15] J.K. Cho, R. Najman, T.W. Dean, O. Ichihara, C. Muller, M.J. Bradley, Captured and cross-linked palladium nanoparticles, J. Am. Chem. Soc. 128 (2006) 6276-6277.

[16] C.J. Orendorff, T.K. Sau, C.J. Murphy, Shape-dependent plasmon-resonant gold nanoparticles, Small 2 (2006) 636-639.

[17] Z. Merican, T.L. Schiller, C.J. Hawker, P.M. Fredericks, I. Blakey, Self-assembly and encoding of polymer-stabilized gold nanoparticles with surface-enhanced Raman reported molecules, Langmuir 23 (2007) 10539-10545.

[18] S.P. Mulvaney, M.D. Musick, C.D. Keating, M.J. Natan, Glass-coated, analyte-tagged nanoparticles: A new tagging system based on detection with surface-enhanced Raman scattering, Langmuir 19 (2003) 4784-4790.

[19] L.M.L. Marzan, I. Lado-Tourino, Reduction and stabilization of silver nanoparticles in ethanol by nonionic surfactants, Langmuir 12 (1996) 3585-3589.

[20] D.G. Duff, G. Baiker, P.P. Edwards, A new hydrosol of gold clusters. 1. Formation and particle size variation, Langmuir 9 (1993) 2301-2309.

[21] M.-C. Daniel, D. Astruc, Gold nanoparticles: Assembly, supramolecular chemistry quantum-size-related properties, and applications toward biology, catalysis, and nanotechnology, Chem. Rev. 104 (2004) 293-346.

[22] C.J. Murphy, T.K. Sau, A.M. Gole, C.J. Orendorff, J. Gao, L. Gou, S. E. Hunyadi, T. Li, Anisotropic metal nanoparticles: Synthesis, assembly, and optical applications, J. Phys. Chem., B 109 (2005) 13857-13870.

[23] H.W. Lu, S.H. Liu, X.L. Wang, X.F. Qian, J. Yin, Z.K. Zhu, Silver nanocrystals by hyperbranched polyurethane-assisted photochemical reduction of Ag, Mat. Chem. Phys. 81 (2003) 104-107.
[24] V.V. Vukovic, J.M. Nedeljkovic, Surface modification of nanometer-scale silver particles by imidazole, Langmuir 9 (1993) 980-983.

[25] A. Henglein, Reduction of $\mathrm{Ag}(\mathrm{CN})_{2}{ }^{-}$on silver and platinum colloidal nanoparticles, Langmuir 17 (2001) 2329$-2333$.

[26] A.C. Templeton, J.J. Pietron, R.W. Murray, P. Mulvaney, Solvent refractive index and core charge influences on the surface plasmon absorbance of alkanethiolate monolayer-protected gold clusters, J. Phys. Chem., B 104 (2000) 564-570.

[27] F.C. Meldrum, N.A. Kotov, J.H. Fendler, Utilization of surfactant-stabilized colloidal silver nanocrystallites in the construction of mono- and multiparticulate Langmuir-Blodgett films, Langmuir 10 (1994) 2035-2040.

[28] M. Sastry, Phase transfer protocols in nanoparticle synthesis, Curr. Sci. 85 (2003) 1735-1745.

[29] W. Wang, S. Efrima, O. Regev, Directing oleate stabilized nanosized silver colloids into organic phases, Langmuir 14 (1998) 602-610.

[30] A. Kumar, P. Mukherjee, A. Guha, S.D. Adyantaya, A.B. Mandale, R. Kumar, M. Sastry, Amphoterization of colloidal gold particles by capping with valine molecules and their phase transfer from water to toluene by electrostatic coordination with fatty amine molecules, Langmuir 16 (2000) 9775-9783.

[31] S.H. Chen, H. Yao, K. Kimura, Reversible transference of $\mathrm{Au}$ nanoparticles across the water and toluene interface: A Langmuir type adsorption mechanism, Langmuir 17 (2001) 733-739.

[32] O. Tzhayik, P. Sawant, S. Efrima, E. Kovalev, J.T. Klug, Xanthate capping of silver, copper and gold colloids, Langmuir 18 (2002) 3364-3369.

[33] N. Gaponik, D.V. Talapin, A.L. Rogach, A. Eychmuller, H. Weller, Efficient phase transfer of luminescent thiolcapped nanocrystalas: From Water to nonpolar organic solvents, Nano Lett. 2 (2002) 803-806.

[34] J. Yang, J.Y. Lee, L.X. Chen, H.-P. Too, A Phase-transfer identification of core-shell structures in Ag-Pt nanoparticles, J. Phys. Chem., B 109 (2005) 5468-5472.

[35] M. Chen, G.W. Diao, C. H. Li, X. M. Zhou, Phase transition of silver nanoparticles from aqueous solution to chloroform with the help of inclusion complexes of $p$ sulfonated calix[4]arene and alkanethiol molecules and its application in the size sorting of nanoparticles, $\mathrm{Na}$ notechology 18 (2007) 175706.

[36] V.V. Vodnik, J.M. Nedeljković, Influence of negative charge on the optical properties of a silver sol, J. Serb. Chem. Soc. 65 (2000) 195-200.

[37] F. Hao, P. Nordlander, Efficient dielectric function for FDTD simulation of the optical properties properties of silver and gold nanoparticles, Chem. Phys. Lett. 446 (2007) 115-118.

[38] P.B. Jonhson, R.W. Christy, Optical constant of the noble Metals, Phys. Rev., B 6 (1972) 4370-4379.

[39] H. Hovel, S. Fritz, A. Hilger, U. Kreibig, M. Vollmer, Width of cluster plasmon resonances: Bulk dielectric functions and chemical interface damping, Phys. Rev., B 48 (1993) 18178-18188. 
[40] D.V Leff, L. Brandt, J.R. Heath, Synthesis and characterization of hydrophobic, organically-soluble gold nanocrystals functionalized with primary amines, Langmuir 12 (1996) 4723-4730.

[41] P. Mulvaney, Surface plasmon spectroscopy of nanosized metal particles, Langmuir 12 (1996) 788-800.
[42] C. Oubre, P. Nordlander, Finite-difference time-domain studies of the optical properties of nanoshell dimers, J. Phys. Chem., B 109 (2005) 10042-10051.

[43] U. Kreibig, G. Bour, A. Hilger, M. Gartz, Optical properties of cluster-matter: Influences of interfaces, Phys. Stat. Sol, A 175 (1999) 351-366.

\section{IZVOD}

\section{REZONANCE POVRŠINSKIH PLAZMONA ORGANOSOLA SREBRA: EKSPERIMENTALNA I TEORIJSKA ISPITIVANJA}

Ivana Vukoje ${ }^{1}$, Dušan Božanić ${ }^{1}$, Jasna Džunuzović ${ }^{2}$, Una Bogdanović ${ }^{1}$, Vesna Vodnik ${ }^{1}$

${ }^{1}$ Univerzitet u Beogradu, Institut za nuklearne nauke „Vinča", Beograd, Srbija

${ }^{2}$ Univerzitet u Beogradu, Institut za hemiju, tehnologiju i metalurgiju (ICTM) - Centar za hemiju, Beograd, Srbija

(Naučni rad)

Cilj ovog rada je eksperimentalno i teorijsko ispitivanje i upoređivanje promena površinskih plazmona nanočestica srebra u vodi i organskim rastvaračima. Nanočestice srebra prečnika $5 \pm 1,5 \mathrm{~nm}$ sintetisane su u vodi redukcijom srebro nitrata pomoću natrijum borhidrida. Nakon toga, nanočestice su prebačene u različite organske rastvarače (hloroform, heksan, toluen i 1,2-dihlorbenzen) pomoću oleilamina. Upotrebljeni rastvarači izabrani su na osnovu razlike u indeksima prelamanja. Na osnovu UV-Vis apsorpcione spektrofotometrije i transmisione elektronske mikroskopije (TEM) potvrđeno je da nema promena u obliku i veličini čestica nakon transfera u organske rastvarače. Apsorpcioni spektri nanočestica srebra u različitim rastvaračima pokazuju promene u položaju površinskih plazmona na osnovu razlike u dielektričnim karakteristikama upotrebljenih rastvarača. Za analizu ovih promena eksperimentalni apsorpcioni spektri su modelovani pomoću Mie teorije za male sferne čestice. Eksperimentalne i teorijske vrednosti položaja površinskih plazmona nanočestica srebra upoređivane su sa Drude teorijom i diskutovana su ograničenja primene same teorije na ponašanja nanočestica srebra u organskim rastvaračima.
Ključne reči: Nanočestice srebra • Organosol $\bullet$ Mie teorija $\bullet$ Drude model 